\title{
Click chemistry towards thermally reversible photochromic 4,5-bisthiazolyl-1,2,3-triazoles
}

\author{
Chenxia Zhang ${ }^{1}$, Kaori Morinaka ${ }^{1}$, Mahmut Kose ${ }^{1,2}$, Takashi Ubukata ${ }^{1}$ \\ and Yasushi Yokoyama*1
}

\section{Letter}

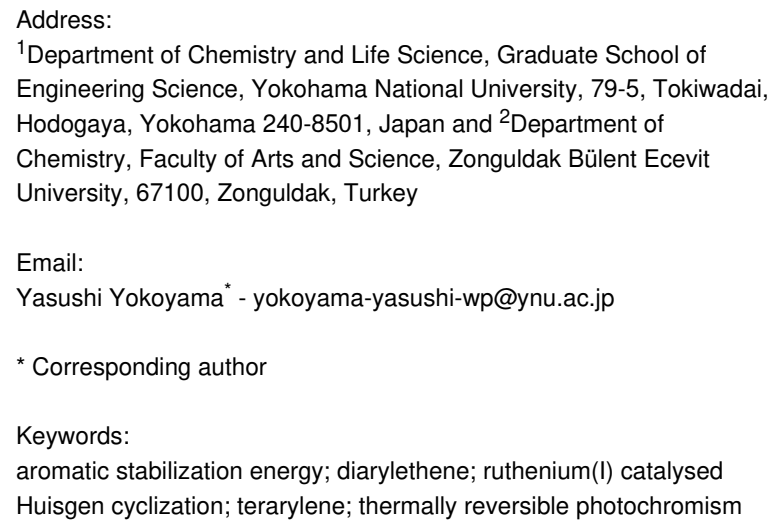

\begin{abstract}
Three new diarylethenes were synthesized from 1,2-bis(5-methyl-2-(4-substituted-phenyl)thiazol-4-yl)ethyne and benzyl azide through $\mathrm{Ru}(\mathrm{I})$-catalyzed Huisgen cyclization reactions. The 4,5-bisthiazolyl-1,2,3-triazoles thus prepared, which belong to the terarylene family, showed thermally reversible photochromism. The absorption maximum wavelengths of the closed forms are longer than other terarylenes reported so far. The thermal back reactions are much faster when the substituents on the terminal phenyl groups are electron-withdrawing cyano groups than when they are electron-donating methoxy groups.
\end{abstract}

\section{Introduction}

Diarylethenes are one of the most widely investigated among the photochromic families [1-3]. They are known to show thermally irreversible photochromism. However, some of them are thermally reversible [4]: (1) when the aromatic stabilization energy of the aromatic rings is large [5]; (2) when the substituent groups on the ring-closing carbon atoms are large [6]; (3) when the substituent groups on the ring-closing carbon atoms are strongly electron-withdrawing [7]; or (4) when the dialkylamino group on the side chain [8] or a carbon atom of the conjugation system in a strained closed form [9] are protonated.
Terarylenes $[10,11]$, one of the closely related families of diarylethenes, are largely thermally reversible $[10,12]$ although some are irreversible when the aromatic stabilization energy of the aromatic rings is small [11]. Their syntheses are usually carried out by the sequential construction of the central aromatic ring at the final stage [10] or the introduction of two aromatic rings to the central aromatic ring [11]. If the construction of three contiguous aromatic-ring arrays can be easily achieved, a new and facile synthesis method for the photochromic family which undergoes $6 \pi$-electrocyclization can be realized [13]. 
Early in the 21st century, Sharpless and co-workers proposed the concept of "click chemistry" [14], which stands for the secure, quick, selective, general and facile reaction between two organic functional groups. In click chemistry, the Huisgen cyclization, which occurs between an organic azide and a terminal alkyne catalyzed by a $\mathrm{Cu}(\mathrm{I})$ ion, was regarded as the representative reaction $[15,16]$. This reaction occurs even in aqueous media, the chemical yield is always high, and the regiochemical structure of the product is always 1,4-disubstituted triazole.

$\mathrm{Cu}(\mathrm{I})$-catalyzed Huisgen cyclization proceeds by the formation of copper acetylide as the intermediate $[15,17]$, resulting in the formation of 1,4-disubstituted triazoles. In contrast, when $\mathrm{Ru}(\mathrm{I})$ complexes are employed as the catalyst, the reaction mechanism is different from the case of $\mathrm{Cu}(\mathrm{I})$, and the major products are 1,5-disubstituted triazoles. Another more important difference is that $\mathrm{Ru}(\mathrm{I})$ catalysts work on the disubstituted alkynes to give 1,4,5-trisubstituted triazoles (Scheme 1) [18,19]. When both substituents of an internal alkyne are aromatic groups, the triazoles thus formed include the hexatriene motif in the structure.

Although a number of photochromic diarylethenes containing triazole groups have been reported [20-31], all of them use the triazole ring as the linker of the second functional molecule with the diarylethene core. To the best of our knowledge, no diarylethenes or terarylenes possessing the triazole ring as one of the components of the hexatriene moiety has been reported to date.

Accordingly, we decided to employ a $\mathrm{Ru}(\mathrm{I})$ catalyst to synthesize 4,5-diaryl-1-substituted-1,2,3-triazoles 1o-3o as possible photochromic compounds (Scheme 2).

\section{Results and Discussion Molecular design and synthesis}

As the organic azide we used commercially available benzyl azide. Since 1,2-bis(5-methyl-2-phenylthiazol-4-yl)ethyne was used in our previous research [32-34], we employed bisthiazolylethynes as the foundation for the skeleton of the target compounds. In order to examine the substituent effects of the terminal phenyl groups on the photochromic properties, compounds with methoxy groups or cyano groups at the para-position of the phenyl groups were also synthesized. To avoid the generation of isomers with a substitution pattern by Huisgen cyclization, the same substituents were introduced to both phenyl groups.

The $\mathrm{Ru}(\mathrm{I})$-catalyzed Huisgen cyclization reaction proceeded rather smoothly to give 1o, 20 and 30 in moderate chemical

$$
\begin{aligned}
& \mathrm{Cu}(\mathrm{I}) \quad \mathrm{R}^{1}=\mathrm{H} \quad\left[\mathrm{R}^{1} \equiv \mathrm{Cu}\right] \stackrel{\mathrm{Cu}(\mathrm{I})}{\text { solvent, } \mathrm{H}_{2} \mathrm{O}} \underset{\mathrm{R}-\mathrm{N}_{3}}{\longrightarrow} \underset{\mathrm{R}^{1}}{\longrightarrow}=\underbrace{\mathrm{N}^{\prime \prime}}_{\mathrm{H}}
\end{aligned}
$$

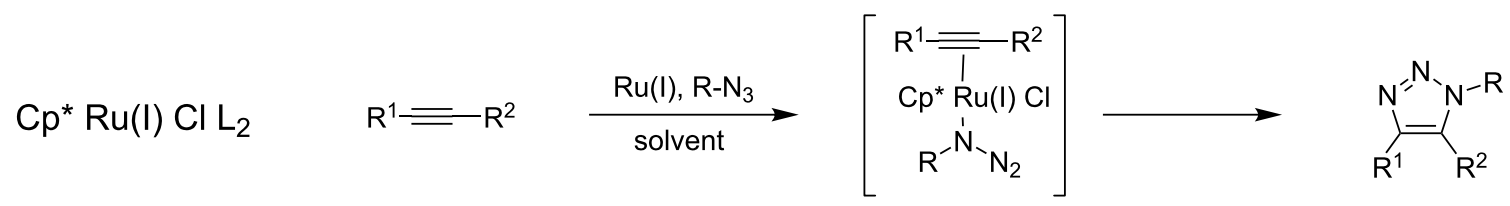

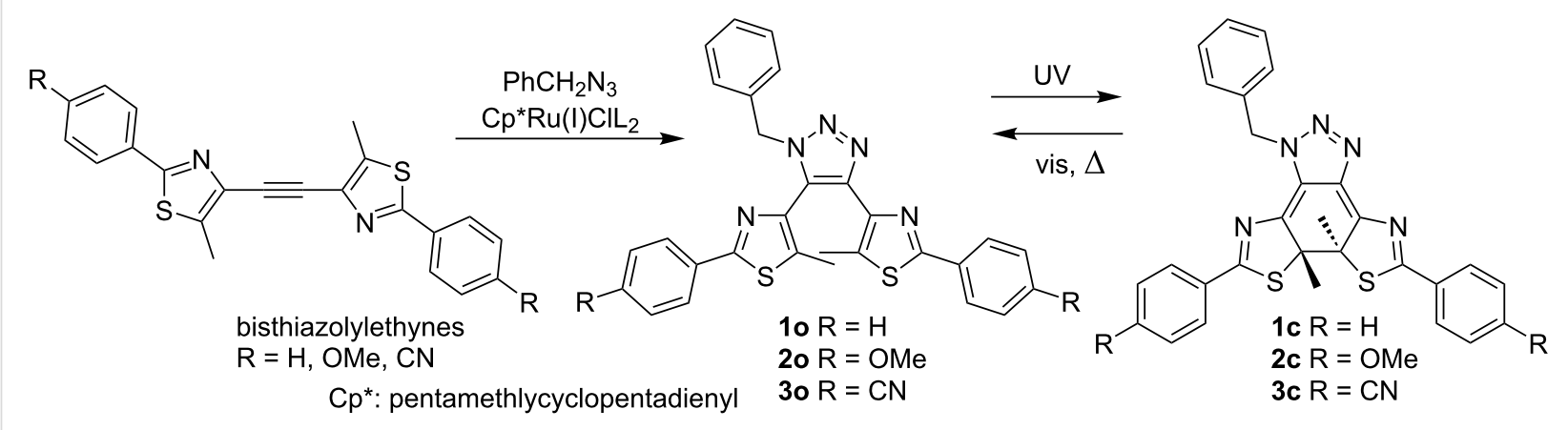


yields of $36 \%, 53 \%$ and $20 \%$, respectively. Since the reported chemical yield of the reaction of tolan, the simplest bisarylethyne, and 2-phenylethyl azide was 63\% [19], it could be considered reasonable that the reactions of the sterically more congested ethynes and benzyl azide gave triazoles with less chemical yields. Details of the synthesis are described in Supporting Information File 1.

\section{Photochromic reactions Photochemical cyclizations}

Triazoles were dissolved in ethanol $(\mathrm{EtOH})$, acetonitrile $(\mathrm{MeCN})$, ethyl acetate (AcOEt) and toluene, and each solution was irradiated with $313 \mathrm{~nm}$ light. The changes in the absorption spectra during UV light irradiation in $\mathrm{MeCN}$ are shown in Figure 1 (spectra of the compounds in the other solvents are shown in Figures S1-S9 in Supporting Information File 1). The absorption spectral properties are summarized in Table 1 together with their predicted absorption maxima obtained by TD DFT calculations in vacuum [35]. Although 10 and 20 showed substantial coloration, 30 showed only a slight coloration at room temperature.
The solvent effects on the absorption maximum wavelengths of the closed forms were not remarkable. The tendency observed was of the absorption maximum wavelength being a few nanometers longer in less polar toluene than for the other solvents.

When the substituents on the terminal phenyl rings are electronwithdrawing cyano groups, the measured absorption maximum of the closed form was about $40 \mathrm{~nm}$ longer than the others in any solvent. The substituent effect observed here is different from the small substituent effect on the closed forms of the representative bisthienylhexafluorocyclopentenes $4 c(\mathrm{R}=\mathrm{H}$, $562 \mathrm{~nm}), 5 \mathbf{c}(\mathrm{R}=\mathrm{OMe}, 570 \mathrm{~nm})$ and $\mathbf{6 c}(\mathrm{R}=\mathrm{CN}, 570 \mathrm{~nm})$ in hexane (Scheme 3) [36]. In triazoles, while the introduction of electron-donating methoxy groups had little effect on the absorption maximum wavelengths, the introduction of electronwithdrawing cyano groups induced a large bathochromic shift. This observation was well-reproduced by TD DFT calculations (Table 1 and chapter SI-4 in Supporting Information File 1).

When the absorption maximum wavelength of $\mathbf{1 c}$, whose central ethene moiety is triazole, is compared with those of the
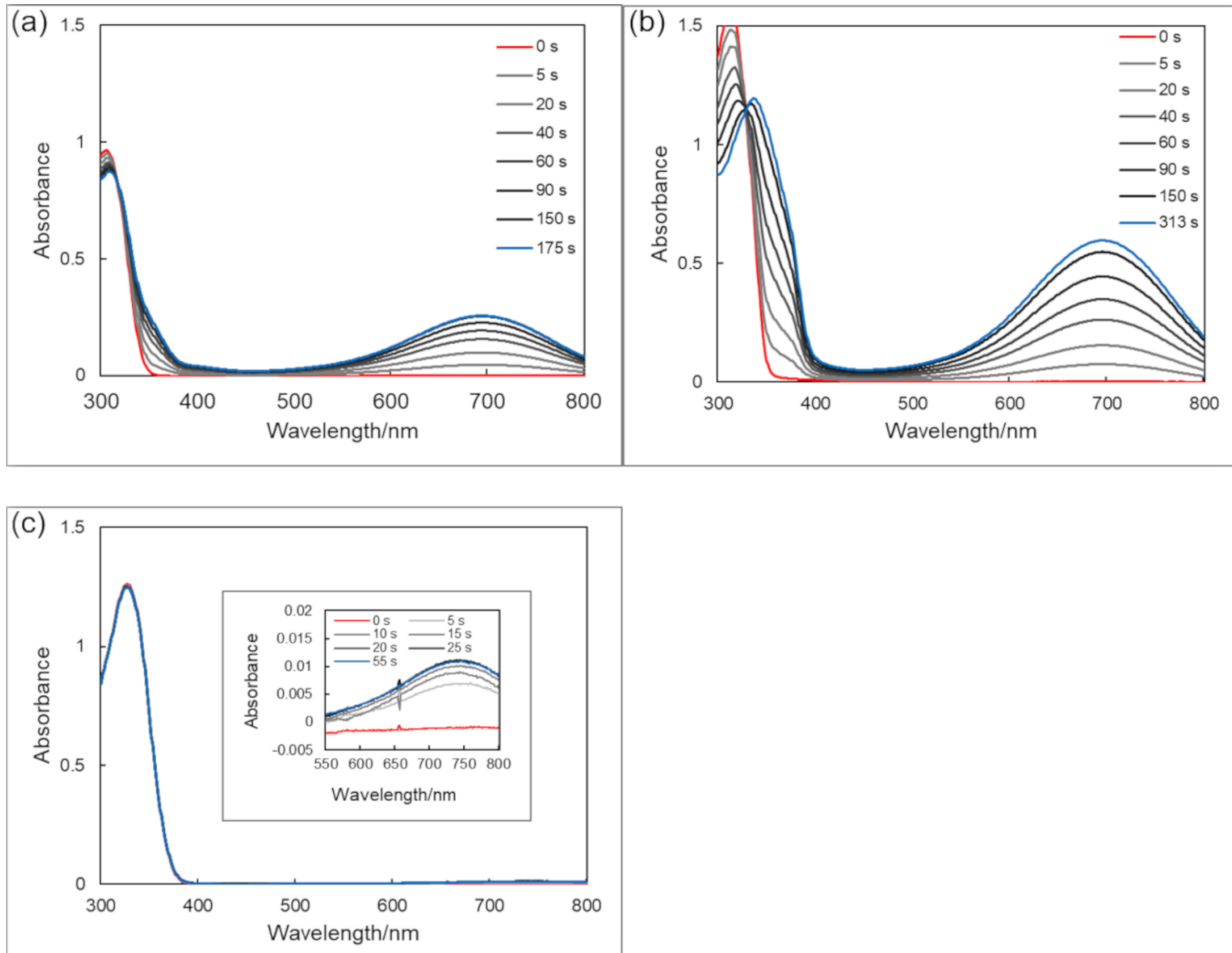

Figure 1: Absorption spectral change of triazoles 1o-3o upon irradiation of $313 \mathrm{~nm}$ light in MeCN at $28^{\circ} \mathrm{C}$. Light intensity: $1.8 \mathrm{~mW} \mathrm{~cm}^{-2}$. (a) 10 . $4.44 \times 10^{-5} \mathrm{~mol} \mathrm{dm}^{-3}$. (b) $20.4 .38 \times 10^{-5} \mathrm{~mol} \mathrm{dm}^{-3}$. (c) $30.4 .73 \times 10^{-5} \mathrm{~mol} \mathrm{dm}^{-3}$. 


\begin{tabular}{|c|c|c|c|c|c|}
\hline Solvent and calculation method & $\mathrm{EtOH}$ & $\mathrm{MeCN}$ & AcOEt & toluene & TD DFT \\
\hline \multirow[t]{2}{*}{$\begin{array}{l}e_{\mathrm{r}}^{\mathrm{b}} \\
E_{\mathrm{T}} \mathrm{Nc}\end{array}$} & $\begin{array}{l}24.55 \\
0.654\end{array}$ & $\begin{array}{l}35.94 \\
0.460\end{array}$ & $\begin{array}{l}6.02 \\
0.228\end{array}$ & $\begin{array}{l}2.38 \\
0.099\end{array}$ & in vacuum \\
\hline & \multicolumn{5}{|c|}{$\lambda_{\max } / \mathrm{nm}$} \\
\hline $1 c(R=H)$ & 692 & 695 & 693 & 698 & 704 \\
\hline 2c $(\mathrm{R}=\mathrm{OMe})$ & 697 & 696 & 693 & 699 & 699 \\
\hline $3 \mathbf{c}(\mathrm{R}=\mathrm{CN})$ & 737 & 739 & 737 & 739 & 759 \\
\hline
\end{tabular}

aln vacuum [35]. ${ }^{\mathrm{b}}$ Relative dielectric constant. ${ }^{\mathrm{C}}$ Normalized $E_{\mathrm{T}}(30)$ value.

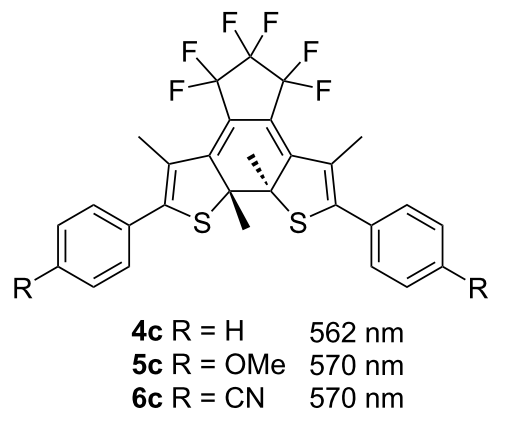

Scheme 3: Wavelengths of absorption maxima of the closed forms of bisthienyletenes in hexane [36].

closely related 7c (cyclopentene) [37], 8c (hexafluorocyclopentene) [38], 9c (thiazole) [39], and 10c (imidazole) [40] in nonpolar solvents, $\mathbf{1 c}$ has a much longer absorption maximum in toluene (Scheme 4, Table 2). It should also be noted that the absorption maximum wavelength is longer when the central ethene moiety is part of the aromatic ring than when it is an isolated ethene in their open-form structures.

Table 2: Absorption spectral data of triazoles and other related photochromic compounds.

\begin{tabular}{ccc} 
& \multicolumn{2}{c}{$\lambda_{\max } / \mathrm{nm}$} \\
\hline Ic & $698^{\mathrm{b}}$ & TD DFT $^{\mathrm{a}}$ \\
\hline 7c & $500^{\mathrm{c}}[37]$ & 704 \\
8c & $525^{\mathrm{d}}[38]$ & 537 \\
9c & $587^{\mathrm{d}}[39]$ & 541 \\
10c & $654^{\mathrm{d}}[40]$ & 636 \\
\hline
\end{tabular}

${ }^{\mathrm{a}}$ In vacuum [35]. ${ }^{\mathrm{b}}$ In toluene. ${ }^{\mathrm{C}}$ In cyclohexane. ${ }^{\mathrm{d}}$ In hexane.

\section{Thermal back reactions}

As expected, all closed forms of triazoles showed thermal back reactions since the photochemical cyclization results in the loss of the aromatic stabilization energy [41] of the three contiguous aromatic rings. The changes in the absorption spectra of thermal decoloration in $\mathrm{MeCN}$ at room temperature are shown in Figure 2.

In order to clarify the nature of the thermal back reaction of triazoles, 1o, 20 and 30 were irradiated with $313 \mathrm{~nm}$ light in four different solvents, and the decrease in the absorbance of the absorption maximum wavelengths in the visible region was observed at three different temperatures. The first order reaction rate constants of the thermal back reactions at different temperatures were then determined. Arrhenius plots of $\ln k$ against $1 / T$ gave pre-exponential factors (A) and Arrhenius activation energy $E_{a}$ of these thermally reversible photochromic triazoles (Figures S10-S13 in Supporting Information File 1). The kinetic data of the thermal back reactions of $\mathbf{1 c}-\mathbf{3 c}$ in toluene are shown in Table 3 together with the literature data of related compounds 9c [39] and 10c [40] shown in Scheme 4.

As shown in Table 3, the thermal back reaction is fast when the aromatic stabilization energy of the central aromatic ring is large. Although $E_{a}$ of $\mathbf{1 0}$ is smaller than that of $\mathbf{1}$ and $\mathbf{2}$, the preexponential factors $(A)$ of $\mathbf{1}$ and $\mathbf{2}$ are about $10^{4}$ times and $10^{3}$ times larger, respectively, than that of $\mathbf{1 0}$.

When the thermal kinetic data of $\mathbf{1 , 2}$ and $\mathbf{3}$ are compared, the thermal back reaction rate of $\mathbf{3}$ is extremely faster than the others, although the central aromatic ring is common to these compounds.

As shown in Table 4, neither electronic charge distribution on the carbon atoms (natural charge [42]) comprising the thermally breaking $\mathrm{C}-\mathrm{C}$ bond, its bond length nor its bond order, which were obtained by DFT calculations of these compounds, did not give a clear explanation for the difference in the reaction rate. Possible evidence of the fast back reaction of $\mathbf{3 c}$ may be found in the bond lengths and Mulliken bond orders between the atoms constructing the conjugation system around the central cyclohexadiene moiety (Scheme 5). 

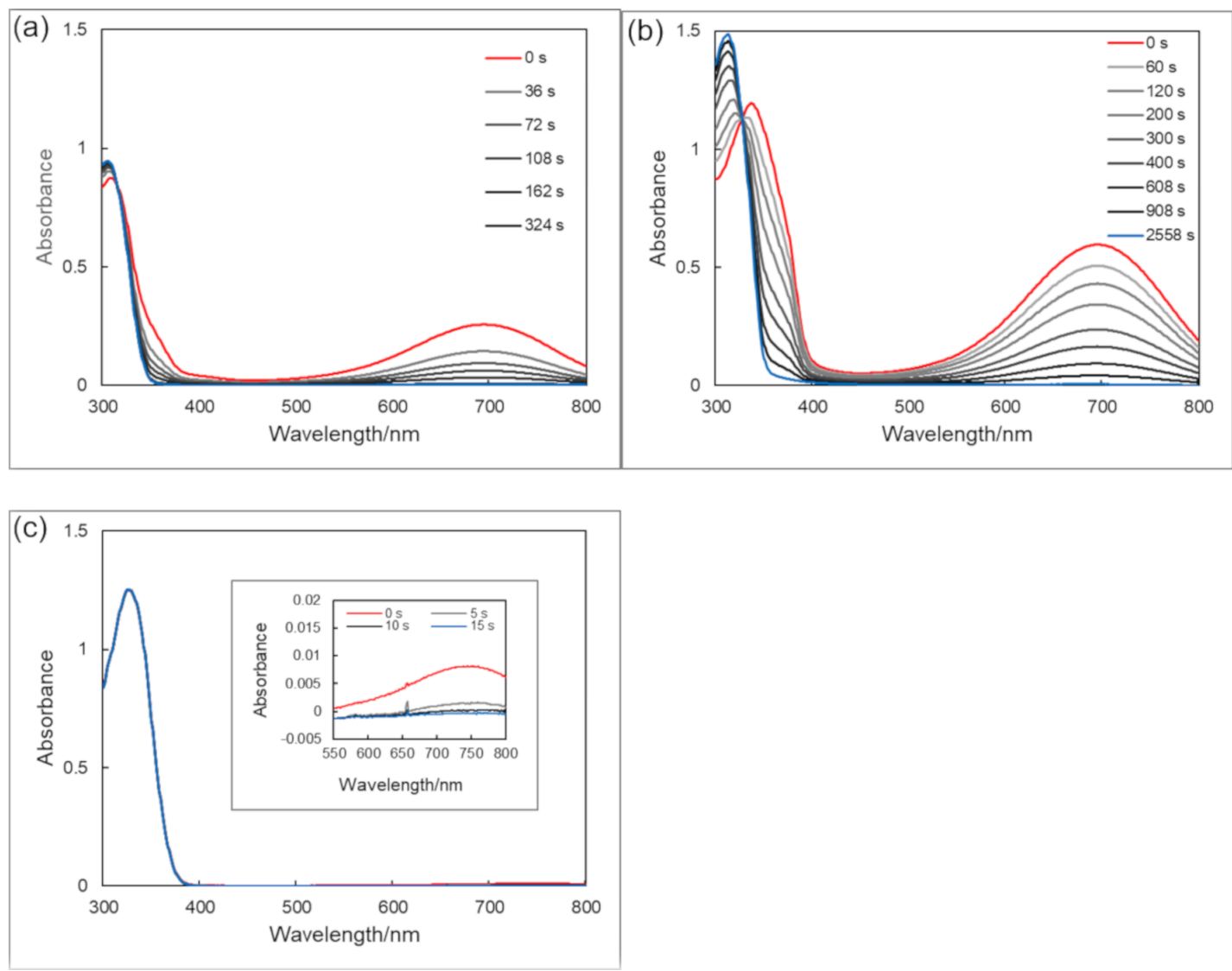

Figure 2: Absorption spectral change of triazoles 1c-3c during the thermal back reaction after $313-\mathrm{nm}$ light irradiation to $10-30$ in $\mathrm{MeCN}$ at $28^{\circ} \mathrm{C}$ Concentration of compounds are the same as in Figure 1. (a) 1c. (b) 2c. (c) 3c.<smiles>[X]C1([X])C(c2nc(C)sc2C)=C(c2nc(-c3ccccc3)sc2C)C1([X])[X]</smiles>

$70 X=H$

$80 X=F$

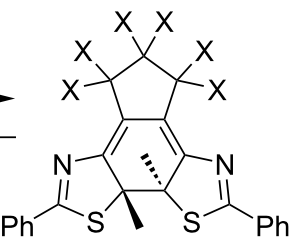

$7 \mathrm{c} X=\mathrm{H}$

$8 \mathrm{c} X=\mathrm{F}$<smiles>[X]C1=C2N=C(c3ccccc3)S[C@]2(C)C2=C3N=C(c4ccccc4)S[C@]3(C)C3=NC(c4ccccc4)=NC3=C1[X]2</smiles>

$90 X=S$ (thiazole)

$9 \mathrm{c} X=\mathrm{S}$ (thiazole)

$100 \mathrm{X}=\mathrm{NMe}$ (imidazole) $10 \mathrm{c} X=\mathrm{NMe}$ (imidazole)

Scheme 4: Photochromism of closely related compounds.

Table 3: Kinetic data of thermal back reactions and aromatic stabilization energy of 1c-3c, 9c and 10c.

\begin{tabular}{|c|c|c|c|c|c|}
\hline & $A / \mathrm{s}^{-1}$ & $E_{a} / \mathrm{kJ} \mathrm{mol}^{-1}$ & $k(293 K) / s^{-1}$ & $t_{1 / 2}(293 \mathrm{~K})^{\mathrm{a}}$ & $\mathrm{ASE}^{\mathrm{b}} / \mathrm{kJ} \mathrm{mol}^{-1}$ \\
\hline $9 c^{c}$ & $7.1 \times 10^{11}$ & 112 & $6.7 \times 10^{-9 d}$ & 3.3 years & 72.9 \\
\hline $10 c^{c}$ & $1.3 \times 10^{9}$ & 85 & $8.7 \times 10^{-7 d}$ & 9.2 days & 78.6 \\
\hline $1 c^{e}$ & $1.21 \times 10^{13}$ & 87.8 & $2.80 \times 10^{-3}$ & $248 \mathrm{~s}$ & 102.0 \\
\hline $2 c^{e}$ & $2.79 \times 10^{12}$ & 87.9 & $6.14 \times 10^{-4}$ & $1130 \mathrm{~s}$ & 102.0 \\
\hline $3 c^{e}$ & $1.26 \times 10^{13}$ & 81.4 & $3.92 \times 10^{-2}$ & $17.7 \mathrm{~s}$ & 102.0 \\
\hline
\end{tabular}

${ }^{a} t_{1 / 2}(293 \mathrm{~K})$ : Half-life at $293 \mathrm{~K}$. b ASE: Aromatic stabilization energy of the central aromatic rings when unsubstituted. Data taken from ref. [41]. ${ }^{\mathrm{C}} \mathrm{In}$ toluene. Data taken from ref. [39] for 9 and ref. [40] for 10 . ${ }^{\mathrm{d}}$ Calculated from $t_{1 / 2}$ at $293 \mathrm{~K}$. ${ }^{\mathrm{I}}$ In toluene. 
Table 4: Natural charge, bond length and bond order of the bondbreaking carbon atoms of triazoles $1 c-3 c$ in the thermal back reactions obtained by DFT calculations.

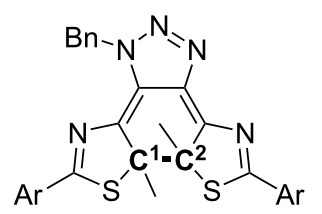

\begin{tabular}{ccccc}
\hline & \multicolumn{2}{c}{ Natural charge } & Bond length/A & Mulliken bond order \\
& $C^{1}$ & $C^{2}$ & $C^{1}-C^{2}$ & $C^{1}-C^{2}$ \\
\hline 1c & -0.198 & -0.204 & 1.547 & 0.933 \\
2c & -0.195 & -0.204 & 1.546 & 0.933 \\
3c & -0.198 & -0.204 & 1.546 & 0.933 \\
\hline
\end{tabular}

${ }^{\mathrm{a} C}$ Calculated by DFT calculations as the number of positive charges [42].
In Scheme $5 \mathrm{a}$, the single bonds of $\mathbf{3 c}$ written in red are shorter than in the other two compounds, implying that they have a stronger double bond character. Similarly, the double bonds of 3c written in green are longer, showing the stronger single bond character. This suggests a stronger bond alteration tendency in $\mathbf{3 c}$ than in $\mathbf{1 c}$ and $\mathbf{2 c}$, and this distinctive character of $\mathbf{3 c}$ can be seen more clearly in Scheme $5 b$.

In addition, since the bond order of the $\mathrm{N}-\mathrm{Bn}$ bond in blue of $\mathbf{3 c}$ is the smallest, it can be reasonably assumed that the lone pair on this nitrogen atom participates in the conjugation in the molecular core more strongly than in $\mathbf{1 c}$ and $\mathbf{2 c}$. This distinctive character of $\mathbf{3 c}$ originates from the electron-withdrawing cyano groups in the molecule.

Data on the terminal phenyl rings in Scheme 5 do not give any convergent tendency of the substituents due to the electron-do-

(a) Bond Length

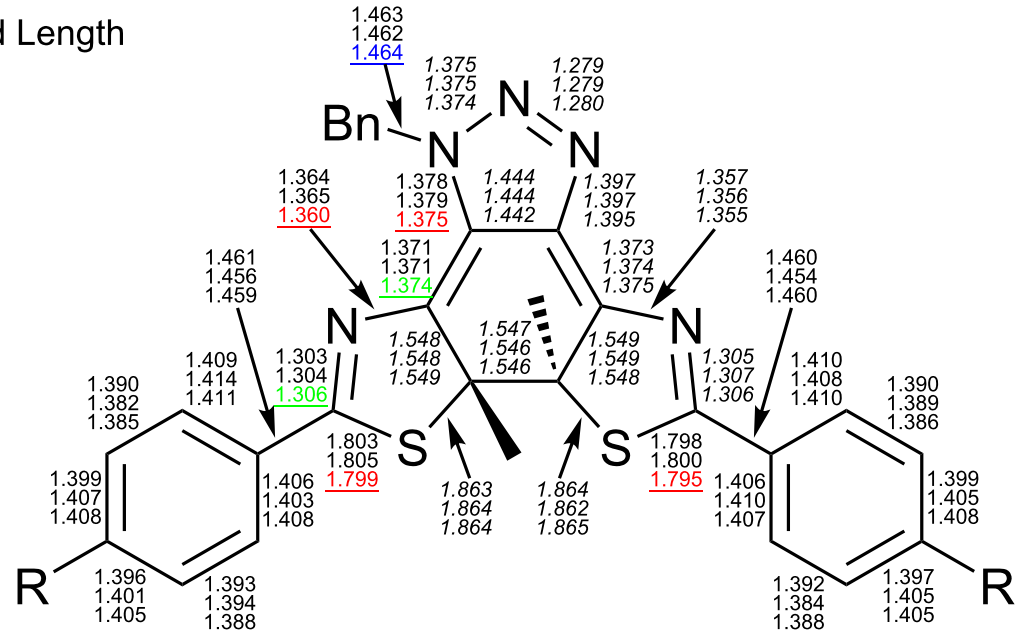

(b) Mulliken Bond Order

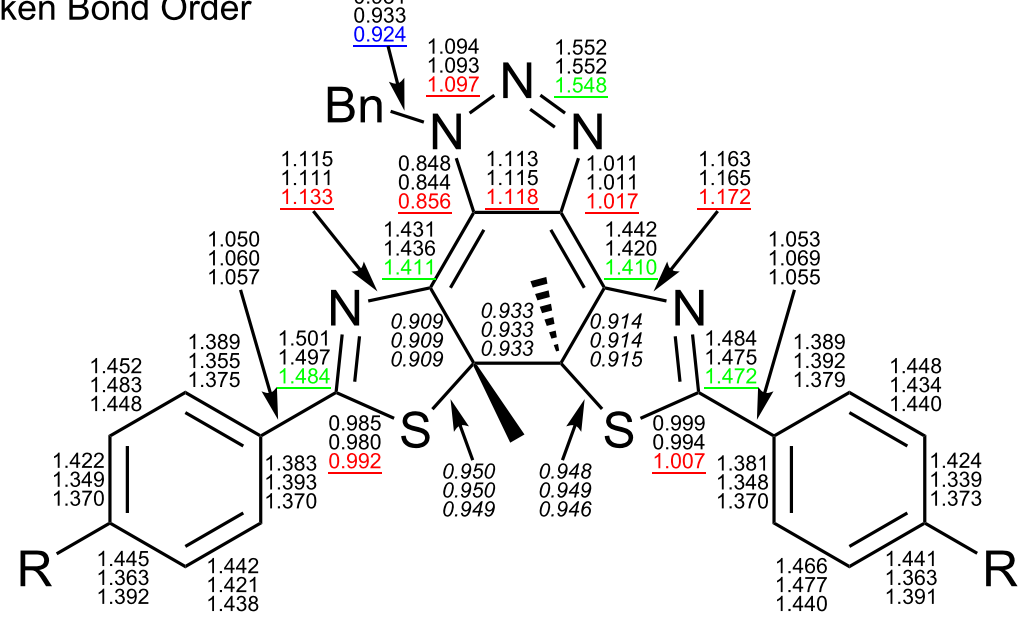

Scheme 5: Bond length (a) (in $\AA$ ) and Mulliken bond order (b) of 1c-3c obtained by DFT calculations. Top number of each set: 1c. Second number: 2c. Bottom number: 3c. Red numbers of 3c: indicates stronger double bond character. Green numbers of $3 c$ : indicates stronger single bond character. Blue numbers of $\mathbf{3 c}$ : indicates weaker bond character. Italic numbers around the central conjugation systems: no significant difference between the three compounds. 
nating character of the methoxy groups in $\mathbf{2 c}$ and the electronwithdrawing character of the cyano groups in $\mathbf{3 c}$. However, it is safe to say the cyano groups in $\mathbf{3 c}$ are pulling the electrons and this effect reaches the nitrogen atom bearing the benzyl group through the conjugation.

Then how does this effect accelerate the thermal back reaction in $\mathbf{3 c}$ ? We propose the conventional reaction mechanism shown in Scheme 6. When the delocalized lone pair on the nitrogen atom moves back from the resonance structures $\mathbf{A}$ and $\mathbf{B}$, it may break the central $\mathrm{C}-\mathrm{C}$ single bond to give the open form, as shown with the arrows. The resonance structures are stabilized more strongly when $\mathrm{R}$ is a cyano group so that the $\mathrm{C}-\mathrm{C}$ bond scission occurs easily. Thus, it is possible to control the rate of the thermal back reaction by: (1) changing the aromatic ring at the ethene moiety, and (2) changing the substituents on the phenyl rings at the peripheral of the molecule.

Finally, we would like to discuss the solvent effects on the thermal back reactions of $\mathbf{1 c}, \mathbf{2 c}$, and $\mathbf{3 c}$. As can be seen in Figure S13, the solvents are classified into two categories: (1) polar solvents (EtOH and $\mathrm{MeCN}$ ) and (2) less polar solvents (AcOEt and toluene). Although the gradient of the lines ( $E$ a) for the same compound in Figure S13a-c are quite similar, the intercepts $(A)$ are clearly different for the two solvent groups of $\mathbf{1 c}$ and $\mathbf{2 c}$. As for $\mathbf{3 c}$, although its categorization is not as clear as $1 \mathbf{c}$ and $\mathbf{2 c}$, differences can still be observed. In general, the thermal back reactions are faster in the more polar solvents, and faster in $\mathrm{MeCN}$ than in $\mathrm{EtOH}$ among these two solvents. However, for 2c, it is faster in $\mathrm{EtOH}$ than in $\mathrm{MeCN}$. This may have originated from the hydrogen-bond formation between EtOH molecules and the methoxy groups in $\mathbf{2 c}$, which reduces the electrostatic repulsion between the methoxy groups and the negatively charged phenyl groups in the intermediate resonance structures $\mathbf{A}$ and $\mathbf{B}$ shown in Scheme 6.

In less polar solvents, the thermal back reactions of $\mathbf{1 c}$ and $\mathbf{2 c}$ are faster in toluene than in AcOEt. However, the reaction of $\mathbf{3 c}$ is the opposite. This could be explained by the strong electronwithdrawing power of the cyano groups in $\mathbf{3 c}$, which enhanced the charge-separation character in the intermediate resonance structures $\mathbf{A}$ and $\mathbf{B}$. These structures are stabilized more strongly in more polar AcOEt than in toluene, and the thermal back reaction rate in AcOEt was increased.

\section{Conclusion}

We have synthesized three novel thermally reversible 4,4'-(1benzyl-1H-1,2,3-triazole-4,5-diyl)bis(5-methyl-2-(4-substituted-phenyl)thiazole)s 1o-3o by Ru(I)-catalysed Huisgen cyclization, which is a type of "click" reaction. They showed thermally reversible photochromism in various solvents. The absorption maximum wavelengths of 1c (with unsubstituted peripheral phenyl groups) and $\mathbf{2 c}$ (with methoxy groups on the phenyl groups) are close to $700 \mathrm{~nm}$, while that of $\mathbf{3 c}$ (with cyano groups on the phenyl groups) was about $740 \mathrm{~nm}$. The thermal back reactions of these compounds proved that $3 \mathbf{c}$ with

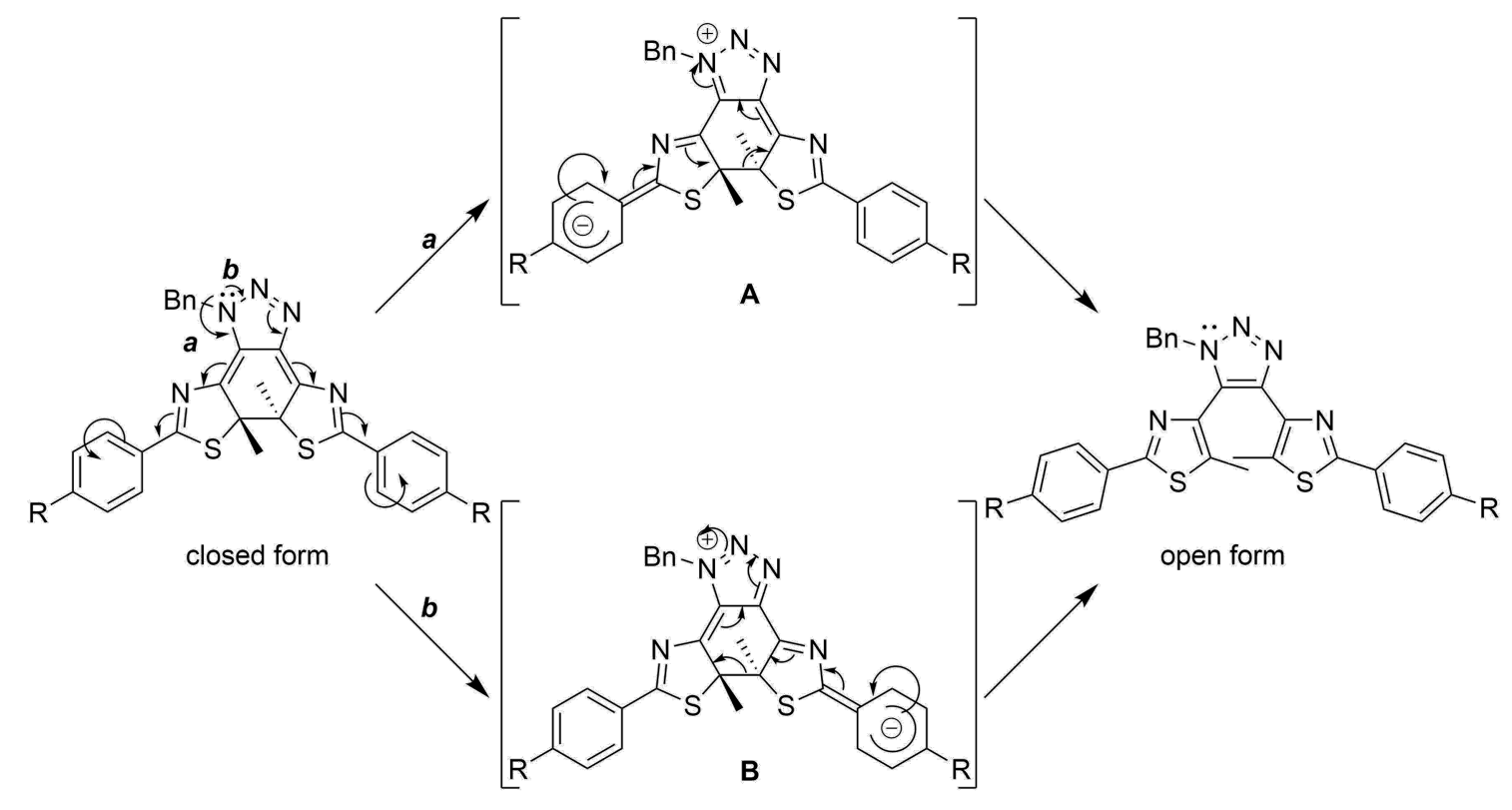


the electron-withdrawing cyano groups is the fastest while $\mathbf{2 c}$ with electron-donating methoxy groups was the slowest. DFT and TD DFT calculations supported these experimental results.

The $\mathrm{Cu}(\mathrm{I})$-catalyzed Huisgen reaction has been used many times to connect two functional molecules. When the Ru(I)-catalyzed Huisgen reaction is employed to connect two functional molecules, the linker itself possesses the thermally reversible photochromic property. Thus, this work can open the door to the creation of promising new materials with highly integrated functions.

\section{Supporting Information}

Experimental details including the synthesis of 1o, 20 and 3o. Changes in the absorption spectra of 10,20 and 30 in ethanol, ethyl acetate and toluene. Analysis processes of the thermal back reactions of $\mathbf{1 o}, \mathbf{2 o}$ and 3o. DFT and TD DFT calculation results of $\mathbf{1 c}, \mathbf{2 c}$ and $3 \mathbf{c}$ and ${ }^{1} \mathrm{H}$ NMR, IR and mass spectra of new compounds.

\section{Supporting Information File 1}

Additional experimental data and spectra.

[https://www.beilstein-journals.org/bjoc/content/ supplementary/1860-5397-15-213-S1.pdf]

\section{Acknowledgements}

This work was supported by MEXT KAKENHI Grant Number JP19050004 in Grant-in-Aid for Scientific Research in Priority Areas "New Frontiers in Photochromism (No. 471)" and JSPS KAKENHI Grant Number JP26107009 in Scientific Research on Innovative Areas "Photosynergetics". The authors are also grateful to the Instrumental Analysis Center of Yokohama National University for their support in the NMR and MS measurements.

\section{ORCID ${ }^{\circledR}$ iDs}

Mahmut Kose - https://orcid.org/0000-0003-2689-6661 Takashi Ubukata - https://orcid.org/0000-0001-5124-4986

Yasushi Yokoyama - https://orcid.org/0000-0002-8654-1320

\section{References}

1. Irie, M.; Fukaminato, T.; Matsuda, K.; Kobatake, S. Chem. Rev. 2014, 114, 12174-12277. doi:10.1021/cr500249p

2. Tian, H.; Yang, S. Chem. Soc. Rev. 2004, 33, 85-97. doi:10.1039/b302356g

3. Irie, M. Chem. Rev. 2000, 100, 1685-1716. doi:10.1021/cr980069d

4. Kitagawa, D.; Sasaki, K.; Kobatake, S. Bull. Chem. Soc. Jpn. 2011, 84, 141-147. doi:10.1246/bcsj.20100274

5. Nakamura, S.; Irie, M. J. Org. Chem. 1988, 53, 6136-6138. doi:10.1021/jo00261a035
6. Kobatake, S.; Uchida, K.; Tsuchida, E.; Irie, M. Chem. Lett. 2000, 29, 1340-1341. doi:10.1246/cl.2000.1340

7. Gilat, S. L.; Kawai, S. H.; Lehn, J.-M. Chem. - Eur. J. 1995, 1 , 275-284. doi:10.1002/chem.19950010504

8. Kobatake, S.; Terakawa, Y. Chem. Commun. 2007, 1698-1700. doi:10.1039/b700177k

9. Jurissek, C.; Berger, F.; Eisenreich, F.; Kathan, M.; Hecht, S. Angew. Chem., Int. Ed. 2019, 58, 1945-1949. doi:10.1002/anie.201812284

10. Krayushkin, M. M.; Ivanov, S. N.; Martynkin, A. Y.; Lichitsky, B. V.; Dudinov, A. A.; Uzhinov, B. M. Russ. Chem. Bull. 2001, 50, 116-121. doi:10.1023/a:1009541605405

11. Kawai, T.; Iseda, T.; Irie, M. Chem. Commun. 2004, 72-73. doi:10.1039/b311334e

12. Kawai, S.; Nakashima, T.; Atsumi, K.; Sakai, T.; Harigai, M.; Imamoto, Y.; Kamikubo, H.; Kataoka, M.; Kawai, T. Chem. Mater. 2007, 19, 3479-3483. doi:10.1021/cm0630340

13. Kochi, J.; Ubukata, T.; Yokoyama, Y. J. Org. Chem. 2018, 83, 10695-10700. doi:10.1021/acs.joc.8b01341

14. Kolb, H. C.; Finn, M. G.; Sharpless, K. B. Angew. Chem., Int. Ed. 2001, 40, 2004-2021. doi:10.1002/1521-3773(20010601)40:11<2004::aid-anie2004>3.3.co;2$\mathrm{x}$

15. Rostovtsev, V. V.; Green, L. G.; Fokin, V. V.; Sharpless, K. B. Angew. Chem., Int. Ed. 2002, 41, 2596-2599. doi:10.1002/1521-3773(20020715)41:14<2596::aid-anie2596>3.0.co;24

16. Kolb, H. C.; Sharpless, K. B. Drug Discovery Today 2003, 8, 1128-1137. doi:10.1016/s1359-6446(03)02933-7

17. Worrell, B. T.; Malik, J. A.; Fokin, V. V. Science 2013, 340, 457-460. doi:10.1126/science.1229506

18. Zhang, L.; Chen, X.; Xue, P.; Sun, H. H. Y.; Williams, I. D.; Sharpless, K. B.; Fokin, V. V.; Jia, G. J. Am. Chem. Soc. 2005, 127, 15998-15999. doi:10.1021/ja054114s

19. Boren, B. C.; Narayan, S.; Rasmussen, L. K.; Zhang, L.; Zhao, H.; Lin, Z.; Jia, G.; Fokin, V. V. J. Am. Chem. Soc. 2008, 130, 8923-8930. doi:10.1021/ja0749993

20. Finden, J.; Kunz, T. K.; Branda, N. R.; Wolf, M. O. Adv. Mater. (Weinheim, Ger.) 2008, 20, 1998-2002. doi:10.1002/adma.200702455

21. Ouhenia-Ouadahi, K.; Métivier, R.; Maisonneuve, S.; Jacquart, A.; Xie, J.; Léaustic, A.; Yu, P.; Nakatani, K. Photochem. Photobiol. Sci. 2012, 11, 1705-1714. doi:10.1039/c2pp25129a

22. Ding, H.; Liu, G.; Pu, S.; Zheng, C. Dyes Pigm. 2014, 103, 82-88. doi:10.1016/j.dyepig.2013.11.022

23. Pu, S.; Ding, H.; Liu, G.; Zheng, C.; Xu, H. J. Phys. Chem. C 2014, 118, 7010-7017. doi:10.1021/jp5001495

24. Maisonneuve, S.; Métivier, R.; Yu, P.; Nakatani, K.; Xie, J. Beilstein J. Org. Chem. 2014, 10, 1471-1481. doi:10.3762/bjoc.10.151

25. Ma, L.; Liu, G.; Pu, S.; Ding, H.; Li, G. Tetrahedron 2016, 72, 985-991. doi:10.1016/j.tet.2015.12.068

26. Duan, F.; Liu, G.; Fan, C.; Pu, S. Tetrahedron Lett. 2016, 57, 1963-1966. doi:10.1016/j.tetlet.2016.03.079

27. Xue, D.; Zheng, C.; Qu, S.; Liao, G.; Fan, C.; Liu, G.; Pu, S. Luminescence 2017, 32, 652-660. doi:10.1002/bio.3234

28. Singh, R.; Wu, H.-Y.; Kumar Dwivedi, A.; Singh, A.; Lin, C.-M.; Raghunath, P.; Lin, M.-C.; Wu, T.-K.; Wei, K.-H.; Lin, H.-C. J. Mater. Chem. C 2017, 5, 9952-9962. doi:10.1039/c7tc03071a

29. Wang, N.; Wang, R.; Tu, Y.; Pu, S.; Liu, G. Spectrochim. Acta, Part A 2018, 196, 303-310. doi:10.1016/j.saa.2018.02.018 
30. Guo, S.; Liu, G.; Fan, C.; Pu, S. RSC Adv. 2018, 8, 22786-22798. doi:10.1039/c8ra03443e

31. Kang, H.; Fan, C.; Xu, H.; Liu, G.; Pu, S. Tetrahedron 2018, 74 4390-4399. doi:10.1016/j.tet.2018.07.002

32. Morinaka, K.; Ubukata, T.; Yokoyama, Y. Org. Lett. 2009, 11 3890-3893. doi:10.1021/ol901497t

33. Ogawa, H.; Takagi, K.; Ubukata, T.; Okamoto, A.; Yonezawa, N.; Delbaere, S.; Yokoyama, Y. Chem. Commun. 2012, 48, 11838-11840. doi:10.1039/c2cc35793c

34. Nakagawa, T.; Miyasaka, Y.; Yokoyama, Y. Chem. Commun. 2018, 54, 3207-3210. doi:10.1039/c8cc00566d

35. DFT and TD DFT calculations were carried out with Spartan'18 (Wavefunction) at the B3LYP/6-31G* level.

36. Irie, M.; Sakemura, K.; Okinaka, M.; Uchida, K. J. Org. Chem. 1995, 60, 8305-8309. doi:10.1021/jo00130a035

37. Herder, M.; Schmidt, B. M.; Grubert, L.; Pätzel, M.; Schwarz, J.; Hecht, S. J. Am. Chem. Soc. 2015, 137, 2738-2747. doi:10.1021/ja513027s

38. Uchida, K.; Ishikawa, T.; Takeshita, M.; Irie, M. Tetrahedron 1998, 54, 6627-6638. doi:10.1016/s0040-4020(98)00330-5

39. Nakashima, T.; Atsumi, K.; Kawai, S.; Nakagawa, T.; Hasegawa, Y.; Kawai, T. Eur. J. Org. Chem. 2007, 3212-3218. doi:10.1002/ejoc.200700074

40. Nakashima, T.; Goto, M.; Kawai, S.; Kawai, T. J. Am. Chem. Soc. 2008, 130, 14570-14575. doi:10.1021/ja802986y

41. Cyrañski, M. K.; Krygowski, T. M.; Katritzky, A. R.; Schleyer, P. v. R. J. Org. Chem. 2002, 67, 1333-1338. doi:10.1021/jo016255s

42. Reed, A. E.; Curtiss, L. A.; Weinhold, F. Chem. Rev. 1988, 88, 899-926. doi:10.1021/cr00088a005

\section{License and Terms}

This is an Open Access article under the terms of the Creative Commons Attribution License (http://creativecommons.org/licenses/by/4.0). Please note that the reuse, redistribution and reproduction in particular requires that the authors and source are credited.

The license is subject to the Beilstein Journal of Organic Chemistry terms and conditions:

(https://www.beilstein-journals.org/bjoc)

The definitive version of this article is the electronic one which can be found at: $\underline{\text { doi:10.3762/bjoc. } 15.213}$ 